\title{
Characterization of the Constitutive Behavior of a Cathode Active Layer in Lithium-Ion Batteries Using a Bending Test Method
}

\author{
P. Gupta ${ }^{1}$ • I.B. Üçel ${ }^{1}$ P. Pudmundson ${ }^{1}$ (D) $\cdot$ E. Olsson ${ }^{1}$
}

Received: 19 December 2019 / Accepted: 19 May 2020 / Published online: 3 June 2020

(C) The Author(s) 2020

\begin{abstract}
Presently used experimental techniques for the characterization of tensile and compressive behavior of active layers in lithiumion batteries have limitations of different kinds. This is particularly true for measurements of compressive properties. Furthermore, the characterizations of time-dependent stress-strain behavior are largely missing. In order to characterize the stress-strain relationship for a dry cathode active layer in lithium-ion batteries, a mechanical testing method is presented that previously has been applied to the testing of optical fibers. The method is based on U-shaped bending of single-side coated aluminum foils, which enables separate measurements of tensile and compressive properties. In particular, the method has clear advantages for measurements of compressive properties in comparison to previously reported techniques. Relaxation experiments are also conducted in order to characterize the time-dependent properties of the dry active layer and to check if these effects could explain the measured hysteresis. It is found that the elastic modulus in compression is significantly larger than the elastic modulus in tension and that the compressive modulus increases with strain level. Contrary, the tensile modulus is approximately independent of strain. Furthermore, hysteresis effects are present at loading-unloading measurements, both for tension and compression. The low values of the measured elastic moduli show that the electrode properties are largely controlled by the binder and carbon additives. It is concluded that the development of particle-particle contacts most likely is the reason for the higher modulus in compression in comparison to tension. The time-dependent effects are significant, primarily for shorter time scales, which explains the relaxation behavior, but they cannot fully explain the hysteresis effects. Most likely non-linear micromechanisms do contribute as well.
\end{abstract}

Keywords Lithium-ion battery electrode $\cdot$ Constitutive properties $\cdot$ U-shape bending test $\cdot$ Time-dependent behavior $\cdot$ Hysteresis . FE simulation

\section{Introduction}

With the rapid increase in the share of electrically powered vehicles, a significant effort for the development of batteries

P. Gudmundson

petergu@kth.se

P. Gupta

priyank@kth.se

İ. B. Üçel

ucel@kth.se

E. Olsson

erolsson@kth.se

1 Solid Mechanics, Department of Engineering Mechanics, KTH Royal Institute of Technology, 10044 Stockholm, Sweden with higher capacity, longer lifetime and a competitive cost is required. Battery lifetime and performance are dependent on material composition, design and operating conditions which makes it necessary to develop methods to capture mechanical degradation in addition to electrochemical aging. Battery electrodes are formed by aqueous slurries, consisting of active particles, carbon black as conducting additives and polymeric binders for the mechanical integrity. The slurry is coated on a metal foil and the wet film is dried to remove the solvent. The film is then calendared to the metal foil in order to enhance gravimetric energy density and improve mechanical stability [1-3]. The active layer can be characterized as a porous material consisting of electrode particles, binder, carbon additives, and voids. Electrode particles in the active layer swell and shrink during electrochemical cycling, which causes internal stresses both at particle and electrode layer levels [4-9]. This may result in mechanical degradation such as particle 
cracking, particle-binder debonding, void formation, local buckling and delamination at microscopic and macroscopic length scales $[10,11]$. The mechanisms that control the damages are a combination of electrochemical and mechanical phenomena $[12,13]$. To develop a physically-based coupled electrochemical-mechanical continuum model, a reliable test method to extract the mechanical properties of dry electrodes is required prior to performing electrochemical-mechanical investigation. In the present paper, the stress-strain relationship for the dry cathode active layer has been characterized.

For porous electrodes, the direct estimation of electrochemical induced stresses is challenging, particularly because lithiation/delithiation needs to be conducted in a controlled atmosphere. To investigate the mechanics of the electrode as a function of electrochemical cycling, various techniques for in-situ stress and strain measurements have been developed. Some of the techniques that provide real time observations include multi-beam optical sensor [14-16], digital-image correlation [8, 17], and nanoindentation [18]. These techniques have been utilized to provide information on various material properties like fracture energy and flow stresses, associated with changes in structural morphology that occur due to the change in the degree of lithiation $[19,20]$.

Several efforts have been made in order to obtain the tensile and compressive properties of battery constituents, including the active layer [21-24]. Tensile properties of dry electrodes have been obtained using uniaxial tensile tests. The tests have been performed by tapping the ends of a rectangular electrode specimen and pulling in tension until final failure [23-26]. The overall response to the tensile resistance has been approximated using a linear combination of the properties of the metal foil and the active layer. Using the rule of mixtures, the elastic modulus of the active layer has been calculated by subtracting the metal foil contribution [23]. However, this method has a drawback since the tensile behavior is strongly dominated by the metal foil resulting in uncertainties when the active layer properties are extracted. It has also been observed that the tests often result in premature failure of electrodes [26].

For measurements of compressive properties, the same methodology cannot be applied since buckling will immediately occur for the thin foils. Instead, other techniques have been applied. Uniaxial compression tests have been performed by placing electrodes in a stack and compressing it to extract the mechanical properties of the active layer $[23,26,27]$. However, undefined contact conditions arise between the layers that make the extraction of compressive properties uncertain. Alternatively, indentation tests have been used to characterize the mechanical properties of the active layer in compression [23]. This method depends on the point of indentation, and the indenter may penetrate the binder or the active material. Furthermore, the compressive strains that control the indentation response are very large in comparison to expected strains in applications [28]. In addition, the evaluation of material properties from indentation testing is not straightforward, especially if the material behavior is unknown [29]. It should also be noted that both the compression and the indentation methods measure compressive properties in the thickness (out-of-plane) direction, unlike the tensile test method which measures in-plane properties. Due to the calendaring process at the manufacturing of electrodes, it can however not be assumed that the in-plane and out-of-plane properties are the same. Noticeably, reliable methods are to large extents still lacking which can capture the averaged mechanical response of active layers in as-calendared form.

Furthermore, one would expect a time-dependent response because the binder exhibits a strong viscoelastic behavior [30] which can be characterized by a relaxation modulus [31]. Therefore, it is crucial to develop a test method that can accurately capture the time-dependent response of the active layer during electrochemical cycling, both in tension and compression.

The reported methods above have certain weaknesses resulting in uncertainties in estimation of the stressstrain relationship for the active layer. Particularly for compressive properties, there is a need for improved testing techniques. The basic idea in the present paper is to use single-side coated specimens in bending tests to estimate the in-plane constitutive behavior of the active layer, both in tension and in compression. By having the active layer on the outside or the inside of the bending curvature, the layer is loaded in tension or compression, respectively. One advantage of bending tests in comparison to tensile testing is that the contribution to the stiffness from the active layer is much larger in bending compared to tension. Hence, the extraction of the active layer properties is much less sensitive to experimental scatter in comparison to tensile testing. Furthermore, compressive properties can be determined without any problems with buckling.

A U-shape bending method was selected to characterize the in-plane mechanical properties of a cathode electrode layer. This method has been used to measure the bending properties of optical fibers [32]. Similar to the electrode layers, the optical fibers are very thin which makes the U-shape bending method advantageous. Due to the porous nature of the cathode active layer, it was expected to have different mechanical responses in tension and compression. For the experiments, single-side coated cathode specimens were studied. The electrode was flipped in a U-shaped bending set-up to obtain the 
behavior in compression. The test was developed to study the behavior of dry specimens in tension and compression. The elastic moduli were extracted from the tests by use of linear elastic beam theory based on small strains and large rotations. In the end of the paper, finite element simulations of the experiments were performed to validate these assumptions in the extraction of the elastic moduli.

\section{Experimental Set-up and Procedure}

\section{Experimental Samples}

The lithium-ion battery electrode studied in this paper is a commercial NMC cell cathode provided by supplier CUSTOMCELLS® with chemistry and material properties specified in Table 1. The specimen is a single-side coated electrode with a specific capacity of $3.5 \mathrm{mAh} / \mathrm{cm}^{2}$. The electrode has a porosity of $51.80 \%$. Fig. 1(a) shows a dry $100 \mathrm{~mm} \times 100 \mathrm{~mm}$ electrode sheet from which samples of length $100 \mathrm{~mm}$ and width $10 \mathrm{~mm}$ are cut out for mechanical testing. Each sample is carefully cut out using Rexel ClassicCut ${ }^{\mathrm{TM}}$ CL420 cutter such that the edges are not destroyed. Figure 1(b) shows the magnified image of the edge which shows only a marginal damage after the specimen is cut-down. The zone of damage is of the order of $0.1 \mathrm{~mm}$ from the edge which should be compared to the specimen width of $10 \mathrm{~mm}$. This damage has a negligible contribution in the measurements of overall bending stiffness of the electrode active layer. Figure 2(a)-(b) shows the cross-section and the top view of the electrode active layer taken by Scanning Electron Microscope (SEM), which shows the distribution of the various constituents.

\section{Specification of the U-Shape Bending Test}

Figure 3(a) shows the U-shape bending test set-up with the electrode sample placed symmetrically between crossheads by gluing the ends of electrodes to the faceplate such that there is no sliding. The faceplates can be moved with varying displacement rates, and the initial gap between the faceplates can be adjusted manually. Figures 3(b)-(c) shows the electrode samples with the active layer subjected to tension and compression.

All the mechanical tests presented in this paper were conducted using a ZwickRoell tensile testing machine equipped with a $50 \mathrm{~N}$ load cell.

\section{Evaluation of Elastic Modulus}

In order to measure the bending stiffness of the electrode, the setup described in Fig. 3 was utilized. The analysis is based on linear elastic beam theory with small strains and large rotations, see Matthewson et al. [32], who applied this analysis to the bending of optical fibers. With a gap opening in the range of $10-30 \mathrm{~mm}$ and electrode of thickness $0.131 \mathrm{~mm}$, it is safe to apply beam theory for the analysis of stresses and deformations. Figure 4 shows the geometry and the coordinate system used.

The curvature, $\kappa$, at any point $(s, \phi)$ is given by,

$\kappa=\frac{d \phi}{d s}=\frac{1}{R}$

where $R$ is the radius of curvature at that point, with $d x / d s=$ $-\cos \phi$ and $d y / d s=\sin \phi$.

The equilibrium equations may be expressed as,

$M=E I \frac{1}{R}-P x$

where $E I$ and $M$ denote the bending stiffness of the electrode and the bending moment, respectively, according to Fig. 3. The solution is presented in [33] and in particular, the relation between the force $(P)$ and the faceplate separation $(\Delta)$ reads,

$P=E I\left(\frac{1.695}{\Delta}\right)^{2}$

Hence, by measuring the force and the faceplate separation, the bending stiffness of the electrode can be obtained.

The bending stiffness $E I$ of the whole electrode can be expressed in terms of the elastic moduli $\left(E_{1}, E_{2}\right)$, the width

Table 1 Chemistry and thickness for the cathode used in the testing

\begin{tabular}{llll}
\hline Component & Material & Thickness $(\mu \mathrm{m})$ & Remarks \\
\hline Cathode current collector & Aluminum AA 1050 & 20 & $\begin{array}{l}\text { Elastic modulus: } 70 \text { GPa } \\
\text { Yield stress }=103 \mathrm{MPa}[33]\end{array}$ \\
Cathode active layer (single-side coated) & $\begin{array}{c}\text { Lithium-Nickel-Manganese- } \\
\text { Cobalt-Oxide (NMC-622) }\end{array}$ & 111 & $\begin{array}{l}\text { Active material proportion: } 86 \% \text { (by weight) } \\
\text { Active particle size: } 5 \mu \mathrm{m} \text { (mean diameter) } \\
\text { PVdF binder: } 7 \% \text { (by weight) } \\
\text { Conductive carbon: } 7 \% \text { (by weight) }\end{array}$ \\
\hline
\end{tabular}


Fig. 1 a Single-side coated cathode NMC-622 (100 mm $\times$ $100 \mathrm{~mm}$ ) with cut-out sample $(100 \mathrm{~mm} \times 10 \mathrm{~mm}) \mathrm{b}$ Magnified image of the edge of electrode sample cut down from NMC-622 sheet
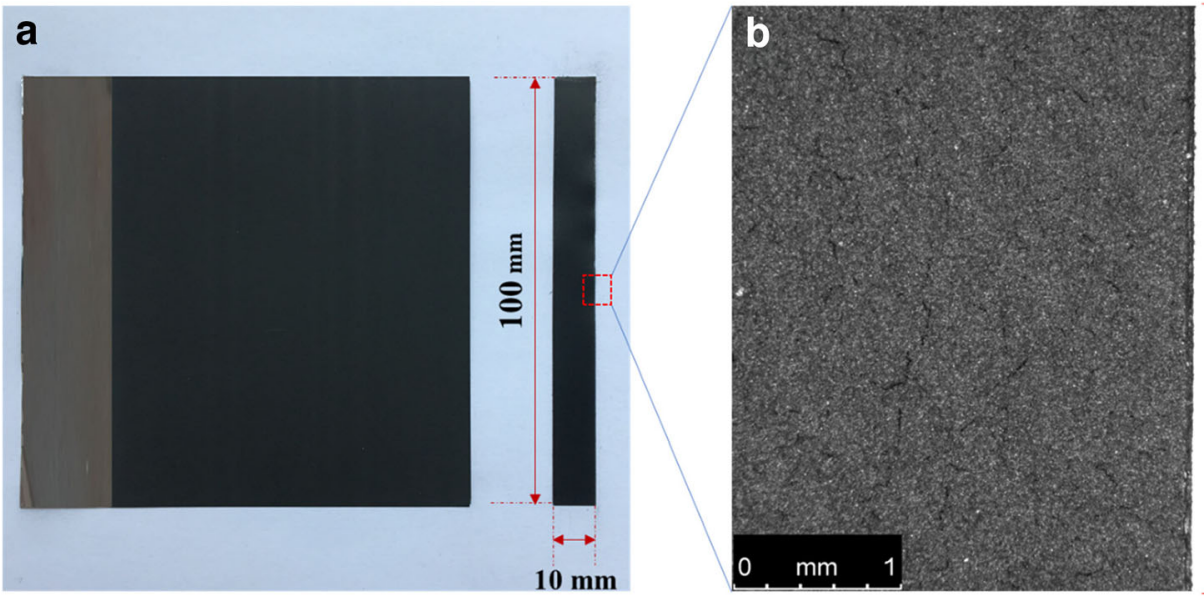

(b), and the thicknesses $\left(t_{1}, t_{2}\right)$ by the use of laminate theory, where the subscripts (1) and (2) denote the active layer and aluminum layer, respectively.

The following equations define the relationship,

$E I=E_{2}\left\{\frac{b t_{2}^{3}}{12}+b t_{2}\left(\bar{y}-\frac{t_{2}}{2}\right)^{2}+\frac{E_{1}}{E_{2}}\left[\frac{b t_{1}^{3}}{12}+b t_{1}\left(\left(\frac{t_{1}}{2}+t_{2}\right)-\bar{y}\right)^{2}\right]\right\}$ where the position of the neutral layer $\bar{y}$ is given by,

$\bar{y}=\frac{\frac{E_{1}}{E_{2}}\left(\frac{t_{1}}{2}+t_{2}\right) b t_{1}+\frac{t_{2}}{2} b t_{2}}{\frac{E_{1}}{E_{2}} b t_{1}+b t_{2}}$

Equations (4) and (5) have been used to evaluate the elastic modulus of the active layer $\left(E_{1}\right)$ from measurements of $E I$, according to Eq. (3) and known values of $E_{2}, b, t_{1}$ and $t_{2}$.
Fig. 2 a Cross-sectional and $\mathbf{b}$ top view of electrode showing the active layer constituents and a layer of Platinum deposited on surface inside FIB/SEM (Images taken with TESCAN GAIA3 by Dr. Fang Liu, Chalmers University of Technology, Gothenberg, Sweden
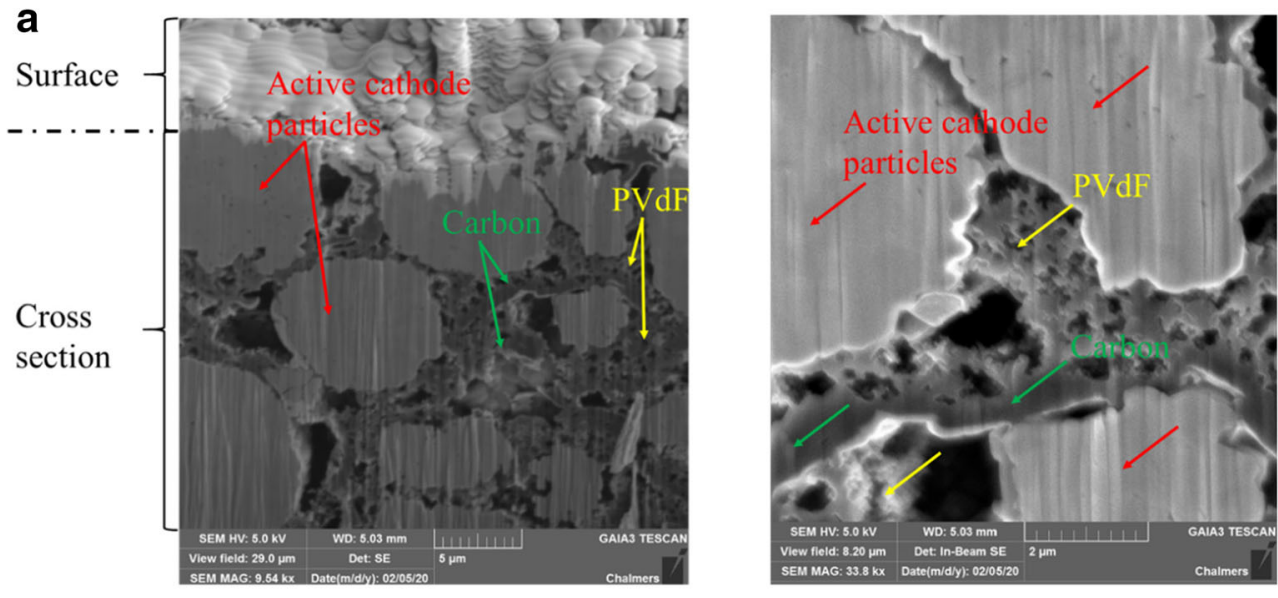

b

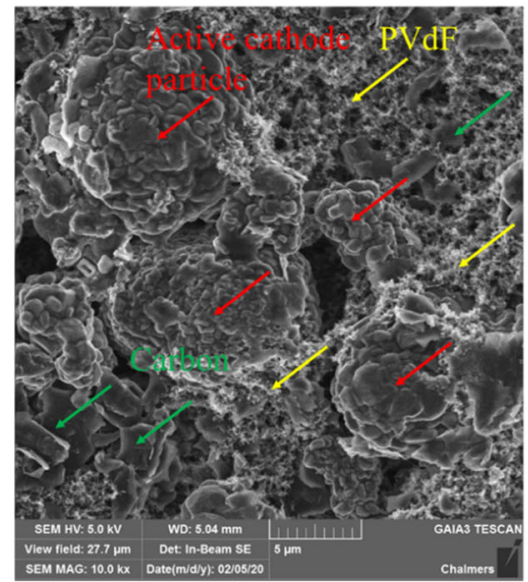


Fig. 3 a Test set-up with electrode sample glued to faceplates; cathode active layer subjected to b Tension and c Compression
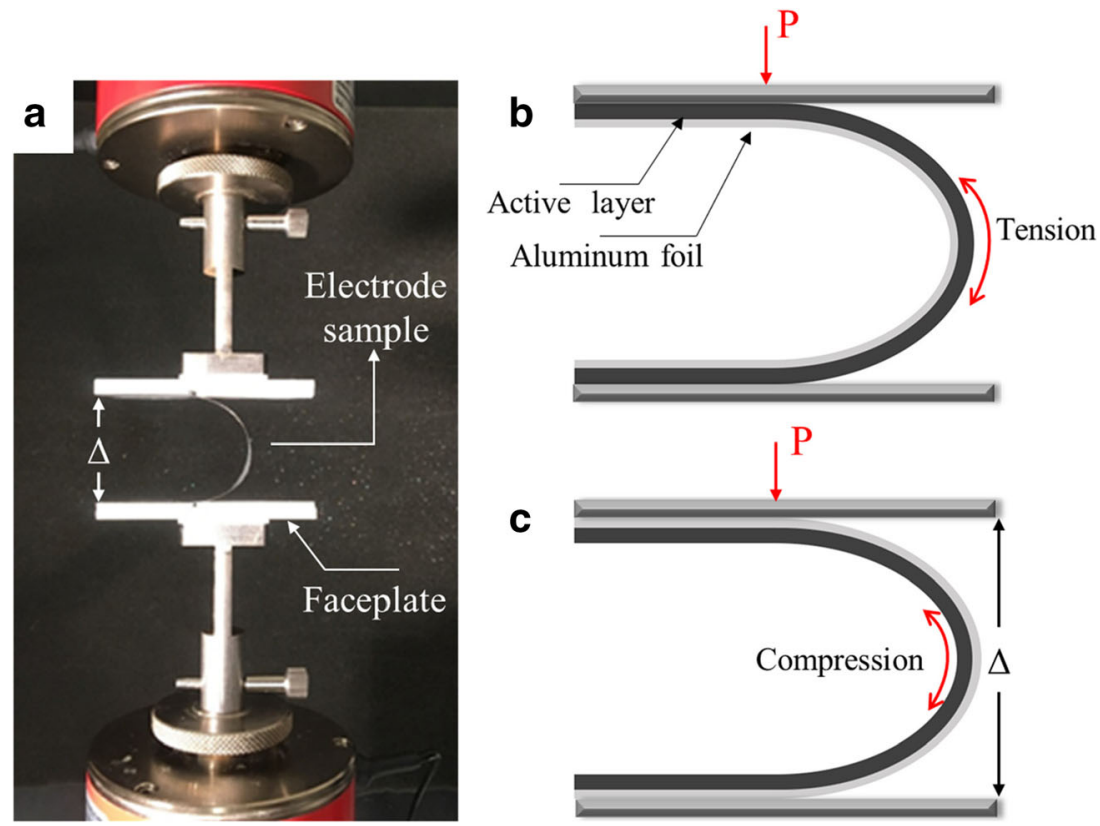

\section{Results and Discussion}

\section{Full Load-Unload U-Bend Tests}

The electrode specimens are first subjected to a full loadunload cycle in tension and compression configuration, see Figs. 3(b) and (c), by altering the faceplate separation from $\Delta=30 \mathrm{~mm}$ to $\Delta=15 \mathrm{~mm}$, followed by immediate unloading back to $\Delta=30 \mathrm{~mm}$. Faceplate separation and the corresponding force are measured with the tensile testing machine. A displacement rate of $30 \mathrm{~mm} / \mathrm{min}$, both in tension and compression, is selected to minimize relaxation effects which may arise from the polymeric binder. In Figs. 5(a) and (b), results from one specimen tested in tension and another specimen tested in compression are shown. To calculate the bending stiffness of the electrode, the force is plotted against $1 / \Delta^{2}$, see Fig. 5(b). It should be noted that all the measurements are performed for unique and virgin specimens and that the width (b) of each specimen is registered after it is cut-down.

As observed in Figs. 5(a) and (b), the electrode specimen with the active layer subjected to compression shows a significantly higher stiffness. The electrode shows a linear behavior during loading and a straight line is fitted to the loading part, see Fig. 4(b). A linear curve fit is also made for the initial unloading path. The obtained slopes of the fitted lines from force vs $1 / \Delta^{2}$ plots give estimates of the bending stiffnesses of the electrode, which can be calculated using Eq. (3). Figure 5(c) shows the root mean square strain level in the active layer as a function of faceplate separation, calculated using the elastic theory [32].

Several experiments are performed, on specimens cutdown from the electrode sheet, in order to check the reproducibility, see Figs. 6(a) and (b). Another set of experiments is performed in order to see the effect of specimen width $(5 \mathrm{~mm}$, $10 \mathrm{~mm}$ and $15 \mathrm{~mm}$ ) on the force response normalized by specimen width, see Figs. 6(c) and (d). Figures 6(a)-(d) demonstrates that the variation in width does not cause a significant change in the width normalized force response. The experimental scatter in the force response may be explained by the stochastic nature of the active layer composition of the selected sample.
Fig. 4 Coordinate system for the bent electrode

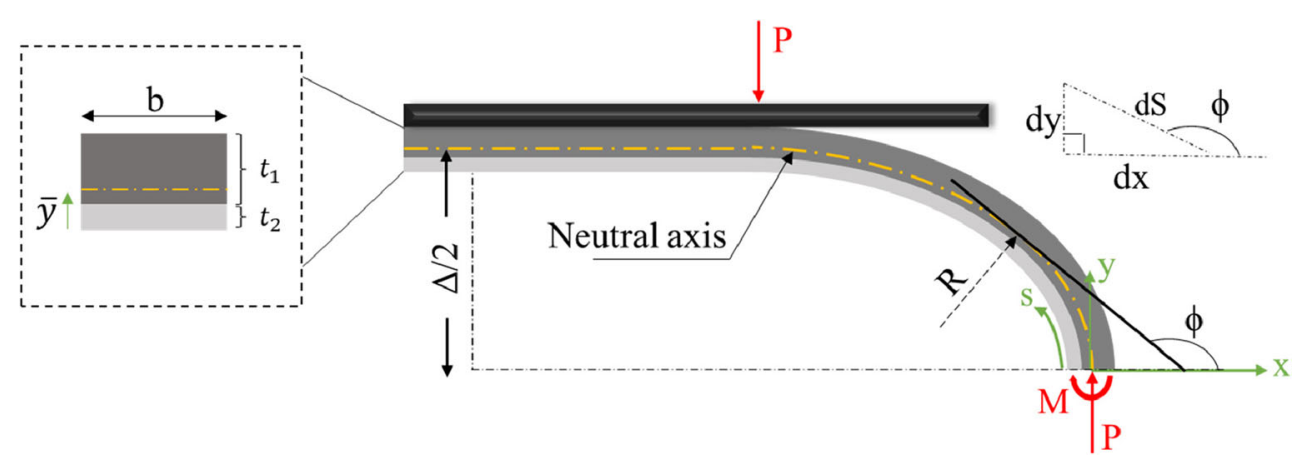


Fig. 5 U-shape bending tests with full load - unload cycle for tension (width $(b)=10.41 \mathrm{~mm}$ ) and compression (width $(b)=9.57 \mathrm{~mm}$ ) configurations (a) Force vs. faceplate separation $(\Delta)$; (b) Force vs. 1/ $\Delta^{2}$ with linear fit to curves denoted by dashed lines; (c) Root mean squared strain in cathode active layer vs. faceplate separation

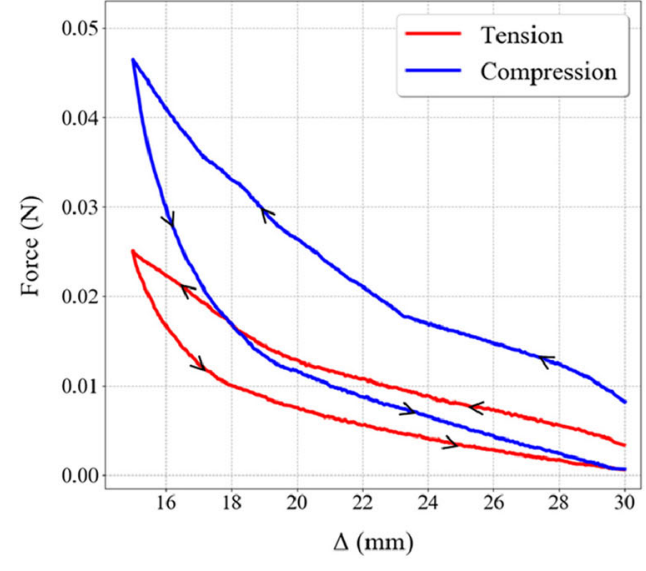

(a)

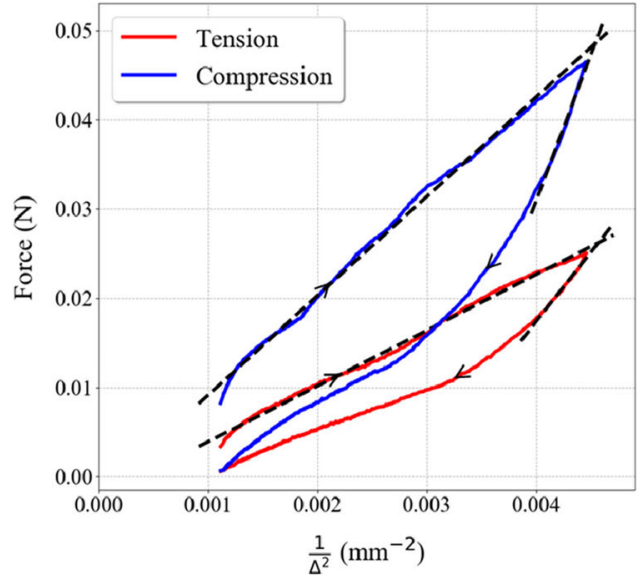

(b)

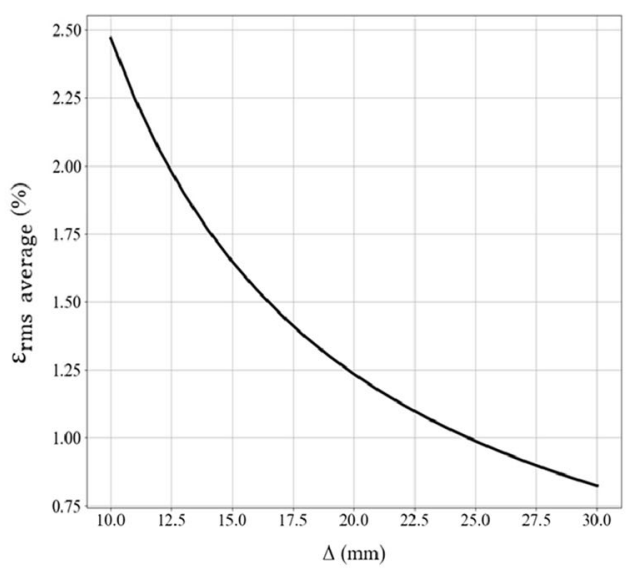

(c)

Using Eqs. (4) and (5), the elastic modulus of the active layer in tension and compression is estimated. The results are presented in Table 2. A significant difference between tensile and compressive loading is observed. The active layer is stiffer in compression. The differences in behavior between tension and compression may be explained by the porous structure of the active layer. At increasing compressive loads, new particle-particle or particle-binder contacts may form which results in an increasing stiffness. This phenomenon is not expected at tensile loading.

Based on elastic calculations described by Eqs. (4) and (5), it is observed that the contribution of the active layer to the bending stiffness of the whole electrode is $85 \%$. This is very different from a corresponding tensile test where the force response to a very large extent is controlled by the stiffness of the current collector. Hence, active layer properties may be extracted with much larger accuracy by application of bending tests instead of tensile tests. It should be noted that the position of the neutral axis lies close to the interface of the active layer and aluminum, for the dimensions of the electrode described in Table 2. The effect of change in aspect ratio strongly influences the position of the neutral axis and the electrode response in bending, which can be captured from $\mathrm{P}$ vs $1 / \Delta^{2}$ curve. With an increase in the thickness of the active layer, its contribution to the overall bending stiffness of the electrode increases.

It is furthermore observed that the unloading elastic moduli are larger than the corresponding loading moduli and that the loading/unloading curves show a marked hysteresis. These observations may arise from time-dependent and/or non-linear effects. The low values of the elastic moduli in comparison to the elastic modulus of the electrode particles [33-35] suggest that the stiffness of the active layer is largely controlled by the binder and carbon additives. The chemical composition of binder, local morphology and the distribution of carbon black strongly affects the mechanical properties of the active layer. Experiments conducted by Chen et al. [30] have shown that the addition of carbon additives changes the mechanical behavior of PVdF and that non-linear effects are caused by the carbon-additives. The hysteresis and the rate effects were explained using a non-linear viscoelastic mod$\mathrm{el}$ in order to describe the mechanical behavior of $\mathrm{PVdF} /$ carbon black composite films [31]. 


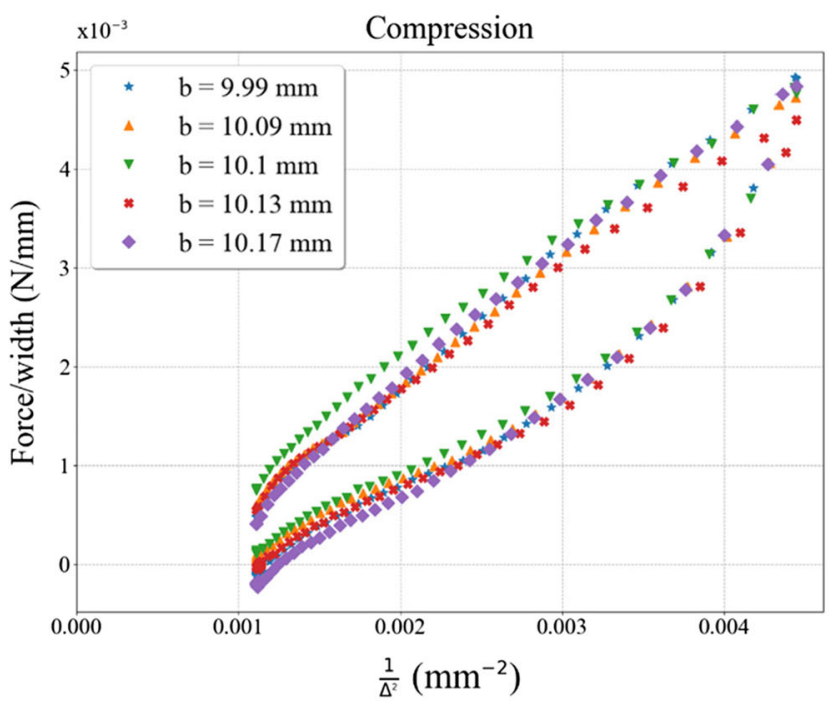

(a)

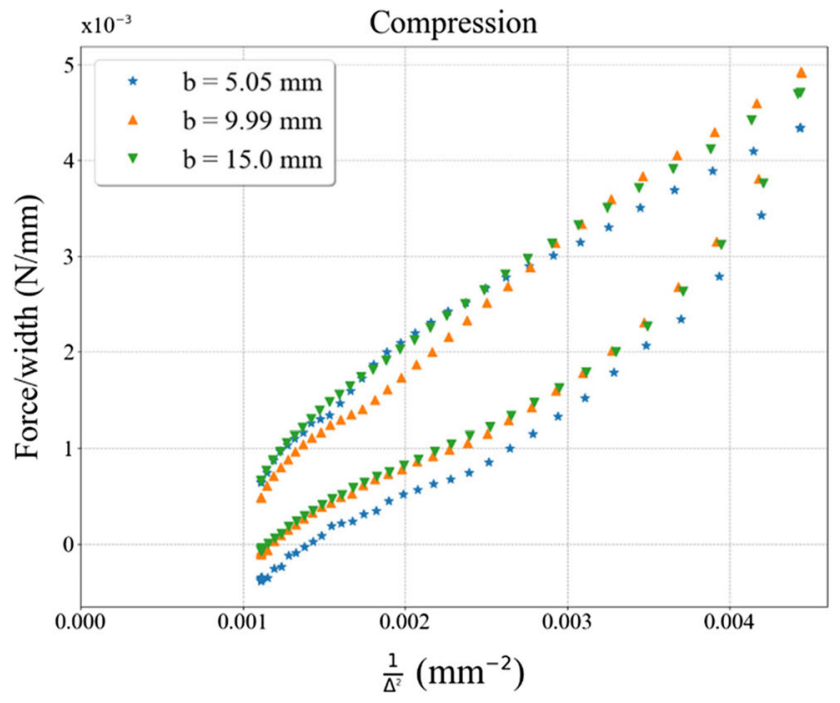

(c)

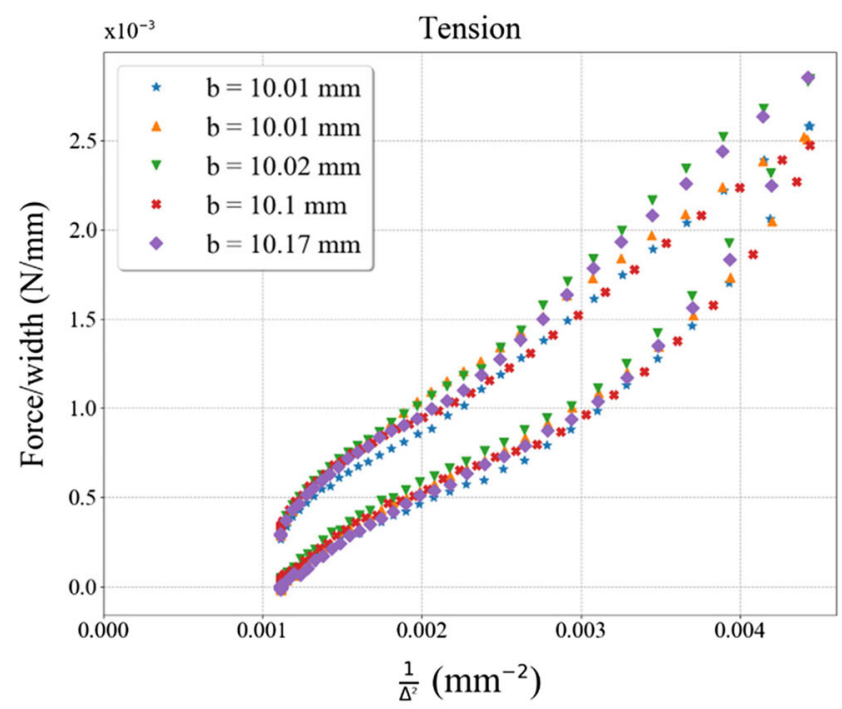

(b)

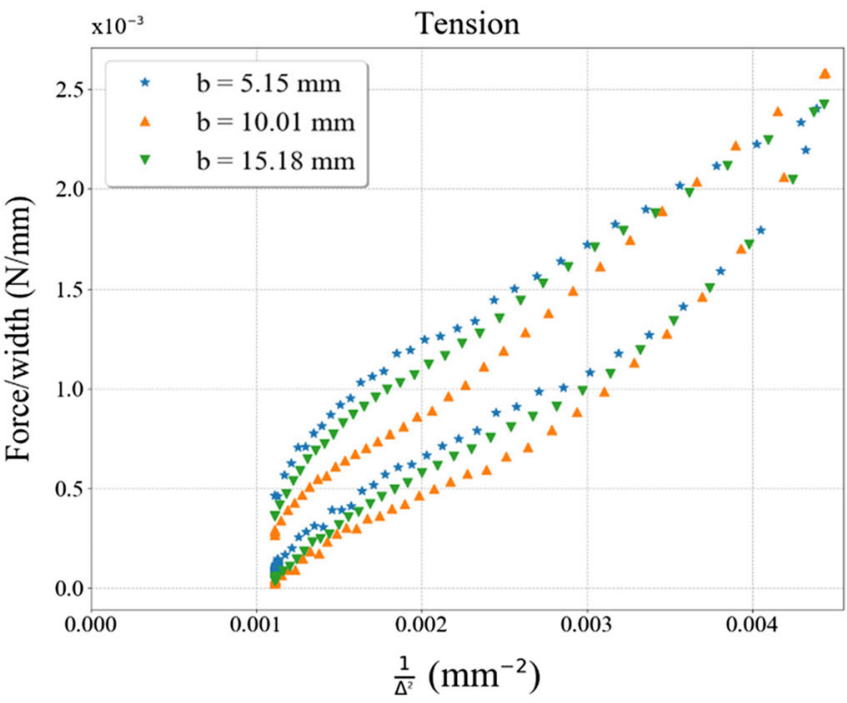

(d)

Fig. 6 U-shape bending tests with specimens subjected to full load-unload cycle in (a) compression configuration with samples of (approximately) same width (b) tension configuration with samples of (approximately) same width (c) compression configuration with samples of different widths (d) tension configuration with samples of different widths. The measured force has been normalized by the sample width (b)

The stresses in the aluminum foil may be estimated from the measurements. At a faceplate separation $(\Delta=$ $15 \mathrm{~mm}$ ), the maximum elastically determined stress in the aluminum foil is $160 \mathrm{MPa}$ and $224 \mathrm{MPa}$ for tension and compression, respectively. With a yield stress of $103 \mathrm{MPa}$ [33], this indicates that plastic deformation most likely develops in the foil. The effects of the plastic deformation on the evaluation of the elastic modulus of the active layer are analysed by finite element simulations, see section on FEM validation of test method. It is shown that the plastic deformation in the foil is limited and that it only has a minor effect on the total response.
Table 2 Elastic moduli of cathode active layer

\begin{tabular}{lll}
\hline Configuration & Loading elastic moduli (GPa) & Unloading elastic moduli (GPa) \\
\hline Tension & $0.33 \pm 0.04$ & $0.90 \pm 0.21$ \\
Compression & $0.70 \pm 0.06$ & $2.36 \pm 0.34$ \\
\hline
\end{tabular}




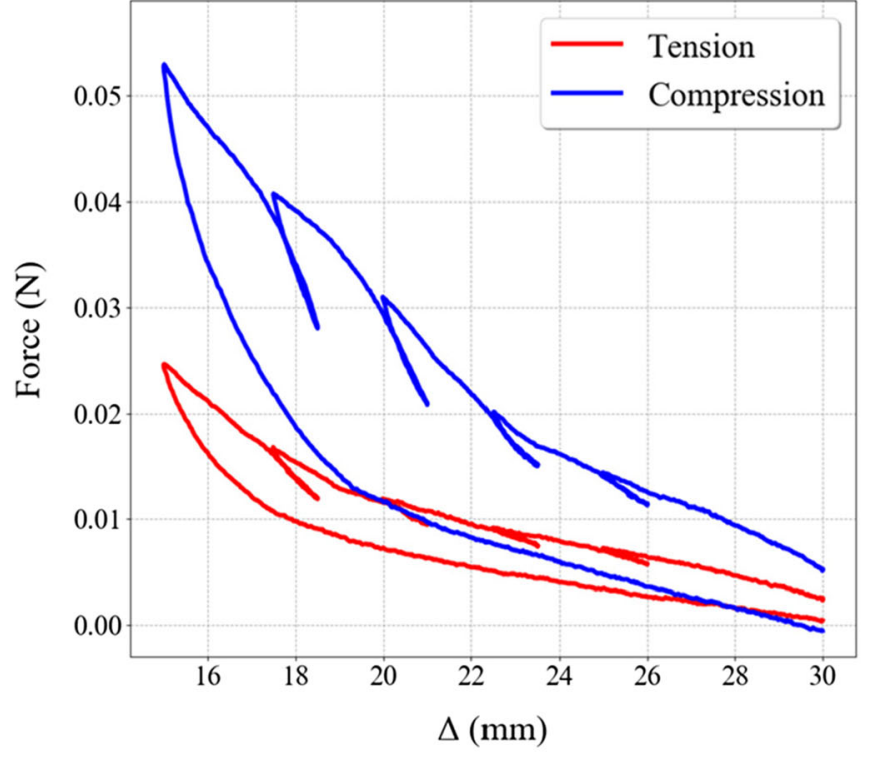

(a)

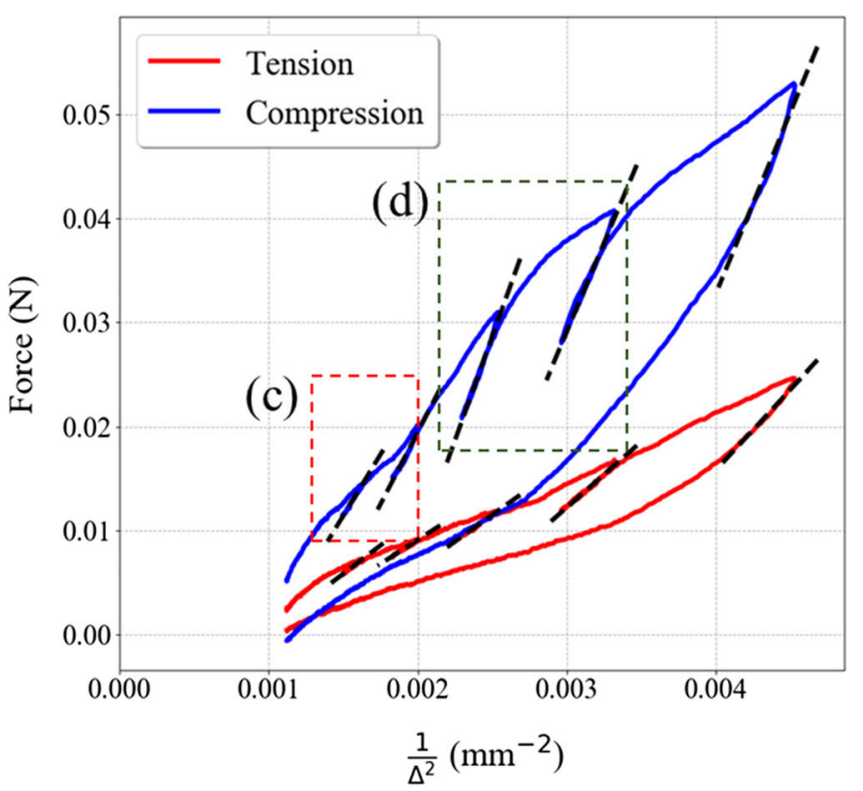

(b)

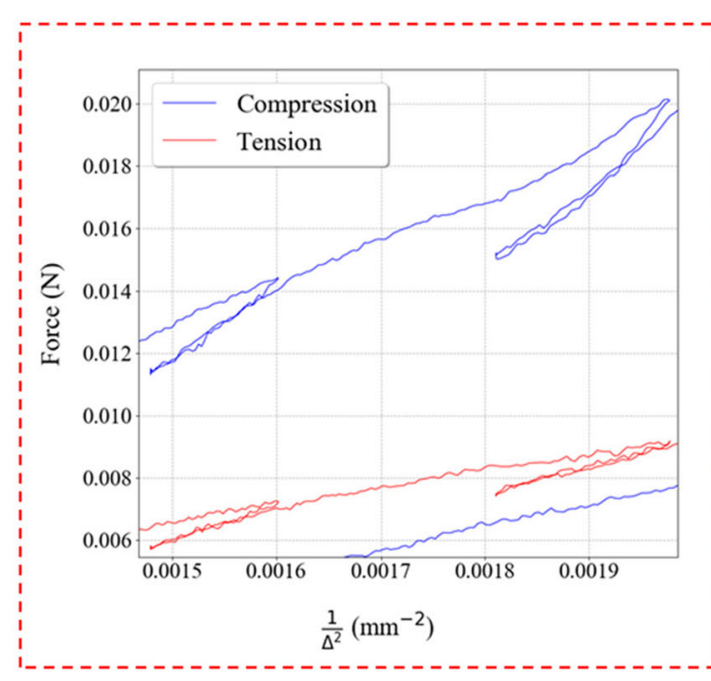

(c)

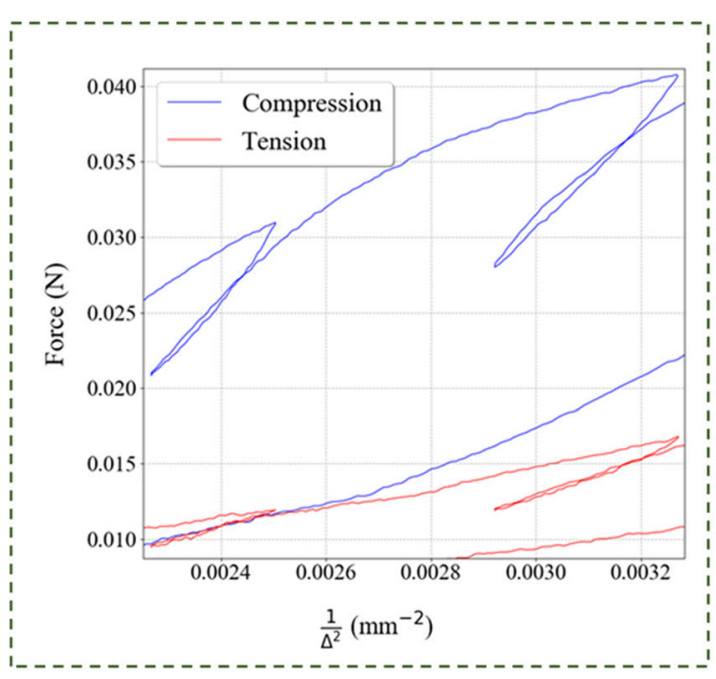

(d)

Fig. 7 U-shape bending tests with unload steps for tension $(b=10.13 \mathrm{~mm})$ and compression $(b=10.12 \mathrm{~mm})$ configuration (a) Force vs. faceplate separation $(\Delta)$ and (b) Force vs. $1 / \Delta^{2}$ with linear fit to unload curves denoted by dashed lines (c) Zoomed view at $\Delta=25 \mathrm{~mm}, 22.5 \mathrm{~mm}(\mathbf{d})$ Zoomed view at $\Delta=20 \mathrm{~mm}, 17.5 \mathrm{~mm}$

Table 3 Calculated elastic modulus for the cathode active layer subjected to tension

\begin{tabular}{llllll}
\hline $\begin{array}{l}\text { Displacement rate } \\
(\mathrm{mm} / \mathrm{min})\end{array}$ & \multicolumn{4}{l}{ Elastic modulus of active layer in tension (GPa) } \\
\cline { 2 - 6 } & $\varepsilon_{r m s}=1.00 \%$ & $\varepsilon_{r m s}=1.10 \%$ & $\varepsilon_{r m s}=1.23 \%$ & $\varepsilon_{r m s}=1.41 \%$ & $\varepsilon_{r m s}=1.65 \%$ \\
\hline 0.1 & 0.95 & 0.78 & 0.84 & 0.76 & 1.06 \\
0.5 & 0.50 & 0.39 & 0.59 & 0.55 & 0.55 \\
1 & 0.89 & 1.17 & 1.09 & 0.91 & 0.90 \\
10 & 0.61 & 0.55 & 0.59 & 0.63 & 0.95 \\
30 & 0.57 & 0.46 & 0.52 & 0.67 & 0.85 \\
\hline
\end{tabular}


Table 4 Calculated elastic modulus for the cathode active layer subjected to compression

\begin{tabular}{llllll}
\hline $\begin{array}{l}\text { Displacement rate } \\
(\mathrm{mm} / \mathrm{min})\end{array}$ & \multicolumn{5}{l}{ Elastic modulus of active layer in compression $(\mathrm{GPa})$} \\
\cline { 2 - 6 } & $\varepsilon_{r m s}=1.00 \%$ & $\varepsilon_{r m s}=1.10 \%$ & $\varepsilon_{r m s}=1.23 \%$ & $\varepsilon_{r m s}=1.41 \%$ & $\varepsilon_{r m s}=1.65 \%$ \\
\hline 0.1 & 1.20 & 1.43 & 1.51 & 1.55 & 1.99 \\
0.5 & 1.04 & 0.86 & 1.79 & 1.72 & 1.52 \\
1 & 0.96 & 0.97 & 1.99 & 1.70 & 2.21 \\
10 & 1.19 & 1.39 & 2.09 & 1.81 & 2.80 \\
30 & 1.46 & 1.79 & 2.74 & 2.28 & 2.33 \\
\hline
\end{tabular}

\section{U-Bend Test with Unloading Steps}

In order to further investigate the effects of strain level on the elastic modulus, tests were conducted with small unloading at varying faceplate separations. The specimen in the tension and compression configuration is loaded by moving the faceplate from $\Delta=30 \mathrm{~mm}$ to $\Delta=25 \mathrm{~mm}$ and then retracted back $1 \mathrm{~mm}$. This 'retraction back' corresponds to the unloading of the specimen. We call this the first unload step. Similarly, the unload steps are employed at $\Delta=22.5 \mathrm{~mm}, \Delta=20 \mathrm{~mm}$ and $\Delta=17.5 \mathrm{~mm}$ with $1 \mathrm{~mm}$ retraction. Finally, the specimen is fully unloaded when the faceplate separation reaches $15 \mathrm{~mm}$. This is done for both configurations, tension, and compression. The force is plotted against the faceplate separation $(\Delta)$, see Fig. 7(a) and against $1 / \Delta^{2}$, see Fig. 7(b), respectively. It should be noted that as the faceplate separation decreases, the bending strain increases, see Fig. 5(c).

Figures 7(c) and (d) show the detailed view of unloadreload steps to portray the mechanical behavior of the electrode more clearly, both in tension and compression. It is observed that under compression, the electrode shows an increase in hysteresis with increasing bending strain, whereas, under tension, the hysteresis is negligible. This difference may be attributed to the evolution of particleparticle contacts as discussed above in relation to compressive loading. Another possible cause for the hysteresis is non-linear behavior of the binder with carbon additives. Frictional effects on the microscale could be an explanation for the difference in hysteresis between unloads in tension and compression.

The bending stiffness at each unload-point is measured by fitting a straight line to the unload curve as described in section 2.3. Using Eq. (4), the elastic modulus of the active layer is calculated at each unload step. The viscoelastic nature of $\mathrm{PVdF}$ suggests a rate-dependent hysteresis; and in order to investigate the effects of rate-dependence on the mechanical behavior of electrode, the experiment is repeated with different displacement rates $(0.1,0.5,1,10 \mathrm{~mm} / \mathrm{min})$. The corresponding elastic moduli are calculated at each unload step. Tables 3 and 4 and Fig. 8 show the calculated elastic modulus at each unload step for the active layer with different displacement rates. The strain level in the active layer is here represented by the root mean square (RMS) of strain based on a linear elastic analysis, see Fig. 5(c).
Fig. 8 Elastic moduli of cathode active layer calculated at different bending strains with varying displacement rates in (a) compression and (b) tension

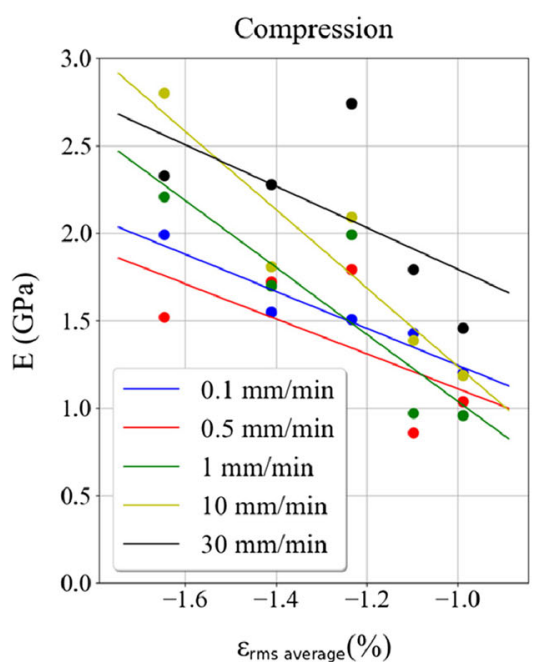

(a)

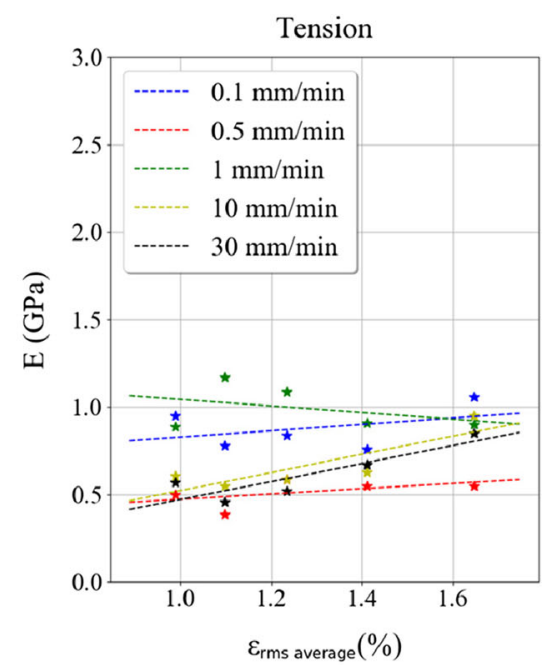

(b) 
Fig. 9 Stress relaxation tests in tension and compression configurations with faceplate separation $(\Delta) 15 \mathrm{~mm}$ kept constant for $6 \mathrm{~h}$ and the corresponding Prony series fit (a) for long time duration and (b) for short time duration

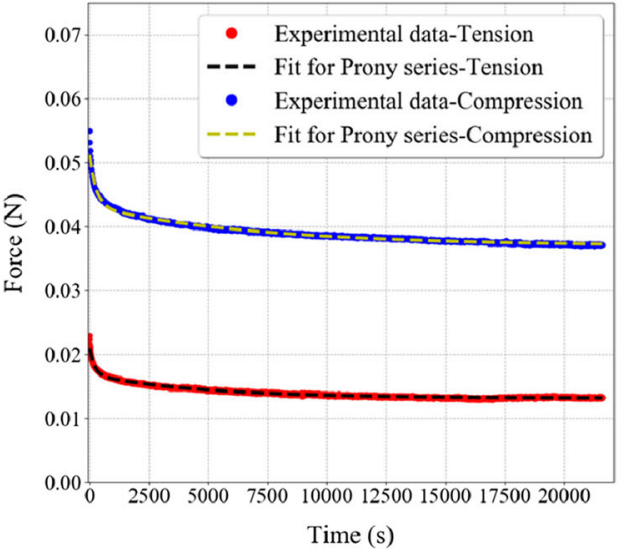

(a)

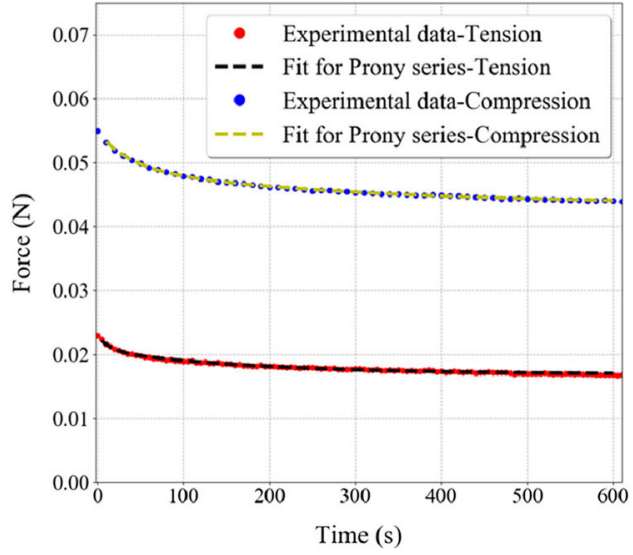

(b)
Based on the elastic calculations, it is evident from the Tables 3 and 4 and Fig. 8 that the active layer has higher unloading stiffness in compression as compared to tension. It is also observed that the compressive elastic modulus increases with bending strain (faceplate separation). However, the variation in elastic modulus in tension with bending strain is considerably smaller. The present data for the elastic modulus in tension and compression have been compared to previously reported measurements $[23,26]$. Due to the uncertainties with alternative testing techniques, there is a large scatter in the reported properties. However, a qualitative agreement with the present data was found.

From Tables 3 and 4 and Fig. 8, a stiffening effect for higher strain rates may be observed but there is a lot of scatter. The observed hysteresis and the strain rate effect in Figs. 8(a)-(b) suggest that time-dependent effects may be of importance.

\section{Relaxation Tests}

In order to characterize the time-dependent effects, relaxation experiments are conducted. The faceplates are moved from $\Delta=30 \mathrm{~mm}$ to $\Delta=15 \mathrm{~mm}$ and are held in a constant position for $6 \mathrm{~h}$. The force and time are recorded using the tensile testing machine. This is performed for both the configurations, tension, and compression. Figure 9(a) shows the mechanical response of the electrode under stress relaxation test.

It is observed that the stresses relax with time. Similar to the previously reported loading/unloading experiment in Figs. 5 and 7, the active layer is stiffer in compression in comparison to tension. The stress relaxation is most likely a result of the time-dependent behavior of the binder. In order to describe the relaxation behavior, a viscoelastic relaxation modulus in the form of a Prony series is applied [30]. The procedure to calculate Prony series parameters is described in the Appendix. The calculated response of the electrode (force vs time) using Prony series was fitted to the experimental data obtained in Fig. 9(a) for both the configurations.

With the faceplate separation of $15 \mathrm{~mm}$, the relaxation modulus of the active layer is evaluated in tension and compression, see Table 5 .

It should be noted that the active layer shows a fast relaxation initially. The long-term modulus must be considered if one is interested in the steady-state response. The relaxation modulus changes slightly if the considered time interval in the curve fitting is changed. Figure 9(b) shows the short-term relaxation response $(600 \mathrm{~s})$ of the electrode and Table 6 shows the fitted Prony series parameters for the active layer.

An attempt to use the time-dependent parameters in Tables 5 and 6 to calculate the force-displacement relationships in Figs. 5 and 7 shows that the hysteresis could only to some extent be explained by the viscoelastic effects seen in Fig. 9.

Relaxation experiments were as well performed with different faceplate separations, $\Delta=10,15$ and $20 \mathrm{~mm}$, in order to observe if the response can be described as linear-viscoelastic. The resulting forces in these experiments are normalized by the strain (which is proportional to $1 / \Delta^{2}$ ) and the relaxation behavior is noted. A linear- viscoelastic behavior would in this setting imply that $P \Delta^{2}$ vs. time response is independent of the
Table 5 Relaxation modulus of cathode active layer based on Prony series fit for $6 \mathrm{~h}$

\begin{tabular}{lll}
\hline Faceplate separation, $\Delta$ & Relaxation modulus (GPa) & Configuration \\
\hline $15 \mathrm{~mm}$ & $E_{1}(t)=0.117+0.065 e^{-t / 211}+0.057 e^{-t / 4807}$ & Tension \\
& $E_{1}(t)=0.344+0.097 e^{-t / 283}+0.074 e^{-t / 6770}$ & Compression \\
\hline
\end{tabular}


Table 6 Relaxation modulus of cathode active layer based on Prony series fit for $600 \mathrm{~s}$

\begin{tabular}{lll}
\hline Faceplate separation, $\Delta$ & Relaxation modulus $(\mathrm{GPa})$ & Configuration \\
\hline $15 \mathrm{~mm}$ & $E_{1}(t)=0.176+0.035 e^{-t / 25}+0.058 e^{-t / 175}$ & Tension \\
& $E_{1}(t)=0.409+0.077 e^{-t / 50}+0.071 e^{-t / 460}$ & Compression \\
\hline
\end{tabular}

gap opening $(\Delta)$. However, the observed response shows a dependence on the applied strain (gap displacement). The differences between the relaxation curves for different strain levels, both for tension and compression, can be described by a strain dependent amplitude with approximately the same time dependence. This suggests a non-linear viscoelastic behavior which must be formulated by an amplitude dependent relaxation modulus. The non-linear behavior may originate from carbon-additives in PVdF binders [30, 31].

\section{FEM Validation of Test Method}

The full load-unload U-bend tests suggest that the plastic deformation may arise in the aluminum foil. The extraction of the elastic modulus of the electrode layer described in Eqs. (1)-(5) assumes that the aluminum metal foil behaves elastically, but plastic deformation in the aluminum foil may affect the validity of the analysis. To investigate if plastic deformation has an influence on the evaluation procedure, a Finite Element (FE) model of the U-shape bending test is created in the commercial software ABAQUS [36]. The model is idealized with homogeneous properties for the active layer and aluminum with constant thickness.

The electrode is modeled using 8- node second-order plane-strain elements. The element sizes are $5 \mu \mathrm{m}$ in the thickness direction and $50 \mu \mathrm{m}$ in the length direction. Convergence is checked by reducing the element sizes to half and no visible difference is found. Furthermore, using the same elastic

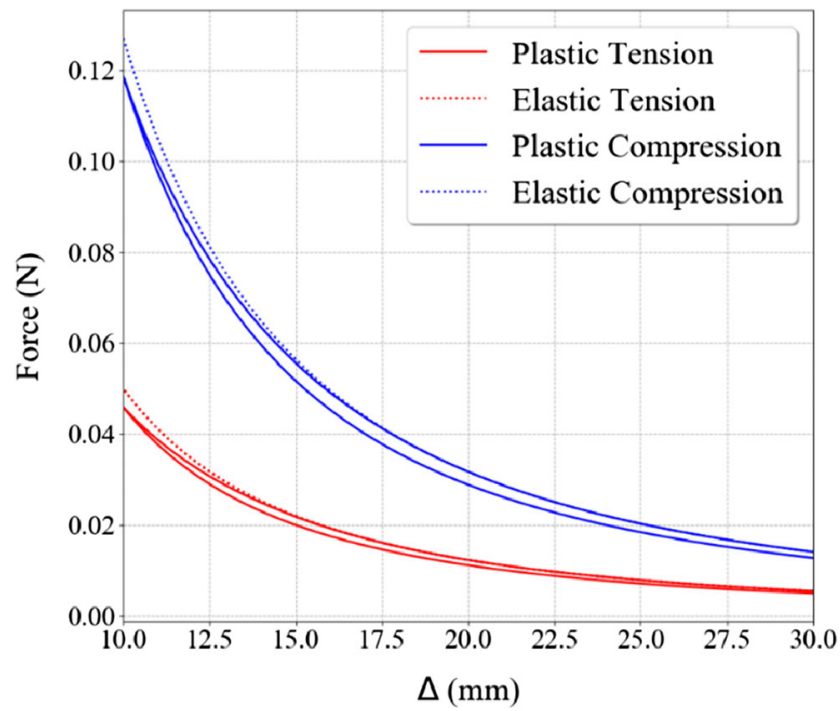

Fig. 10 Simulated force - gap opening relationship using elastic and an elastic-ideally plastic model for the aluminum metal foil properties of the aluminum foil and the electrode material, a good agreement is found with Eq. (3). The faceplates are considered rigid and contact is modeled between the faceplates and the electrode. Aluminum is modeled as an elastic-ideally plastic material with elastic modulus of $70 \mathrm{GPa}$, Poisson's ratio of 0.3 , and yield stress of $103 \mathrm{MPa}$ based on data in [33]. The cathode active layer is modeled as an elastic material using the loading elastic moduli in Table 2 and a Poisson's ratio of 0.1 .

The electrode is loaded in controlled displacement up to a faceplate separation of $10 \mathrm{~mm}$ and then completely unloaded. The compression force is recorded continuously. The results of this investigation are shown in Fig. 10 where the compression force is presented as a function of faceplate separation $\Delta$. These curves may be compared to the corresponding experimental results in Fig. 5. If, for example, the forces at $\Delta=$ $15 \mathrm{~mm}$ are compared, a difference of $5-10 \%$ is observed. This difference is of the same order as the scatter between different specimens, see Table 2. The main conclusion from the finite element calculations is that the difference between purely elastic and elastic-plastic simulations is very small. Hence, it is concluded that the evaluation of elastic and viscoelastic properties of cathode active layer is not affected by plastic deformations in the aluminum metal foil.

\section{Conclusions}

The reported experiments have shown that the U-shape bending test method is well suited for measurements of the average mechanical behavior of electrodes. In particular for compressive properties, it has clear advantages in comparison to alternative methods. A disadvantage of the method is that the specimens show inhomogeneous stress and strain fields. Hence, based on load and displacement measurements, only the average behavior can be captured. For elastic deformations, this is not a problem, but for a non-linear constitutive behavior the method can not give exact information about local properties.

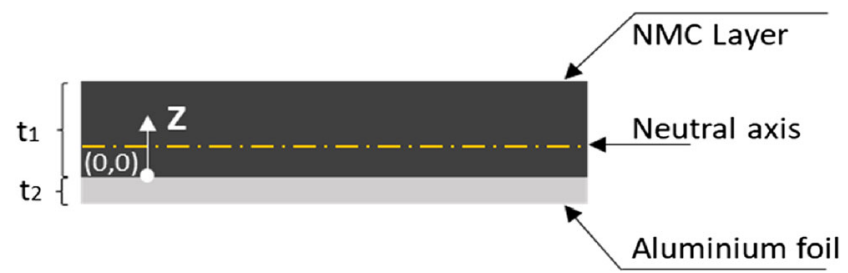

Fig. 11 Schematic of electrode layer 
It is clear that the stiffness in compression is larger than in tension and that the compressive stiffness increases with increasing strain contrary to the behavior in tension. This can most likely be explained by the evolution of particle-particle and particle-binder contacts in the active layer. Investigations of metallic powder compaction have for example clearly shown that an increase in the number of contact points has a significant stiffening effect [37].

The low values of elastic moduli that are reported strongly indicate that the mechanical behavior is largely controlled by the binder properties, at least for the strain levels that are considered here. Also, the measured time-dependent behavior indicates that the binder is strongly controlling the constitutive behavior. The observed relaxation response suggests that the carbon-additives affects the mechanical properties of the electrode active layer and a non-linear viscoelastic model should be developed which takes into account the overall contribution from all the constituents. Experiments have shown that the mechanical properties of the PVdF binder are affected by carbon additives particularly at higher strain levels and a non-linear viscoelastic model has been proposed in the literature to explain hysteresis effects of $\mathrm{PVdF} /$ carbon additives active layers [30].

It is not expected that the electrode particles do show a viscoelastic response. Based on relaxation experiments, a viscoelastic model was derived based on a Prony series. Applications of this model to loading-unloading both in tension and compression resulted in a hysteresis effect. The measured hysteresis could however not fully be explained by viscoelastic effects. Most likely non-linear micro mechanisms, like friction and contact, in addition to non-linearities of carbon-additives do as well contribute. The relaxation experiments also showed that the time-dependent effects are most important for shorter time scales, less than one hour. For longer times. The electrode shows a much smaller time dependence. The evaluated mechanical properties of the dry electrode active layer can serve as input for the development of electrochemical-mechanical continuum models which will enhance the understanding of mechanical response under electrochemical cycling.

The elastic analysis and the finite element simulations show that plastic deformation may develop in the aluminum foil at larger bending curvatures. The finite element results show however that this effect only has a minor influence on the evaluation of elastic stiffness in the cathode active layer. Plastic deformation in the metal foil may as well develop in different battery designs showing large bending curvatures. This phenomenon could have an influence on the microlevel stress state in the active layers and it deserves a closer investigation.

In order to understand the mechanical behavior in more detail, it will be necessary to develop micromechanical models that can capture the evolution of contact conditions in the porous material. It is believed that such investigations will lead to a better understanding and also to knowledge about microstructural stress levels that control damage evolution like particle cracking and particle-binder debonding.

In a battery, compressive or tensile loading results from swelling and shrinking of electrode particles. Repeated charging may lead to fatigue at the microstructural level. To be able to characterize damage evolution and fatigue, it will be important to conduct mechanical measurements concurrently with electrochemical charging and discharging in parallel to the development of micromechanical models. These types of experiments and analyses are planned in the near future.

Acknowledgments The financial support from the Swedish Energy Agency under contracts 45387-1 and 45514-1 is gratefully acknowledged. The micrographs in Fig. 2 were kindly provided by Docent Fang Liu at Chalmers University of Technology, Sweden. The authors would like to thank professor Göran Lindbergh and assoc. professor Rakel Wreland Lindström at the department of Applied Electrochemistry, $\mathrm{KTH}$, for their insights and discussions during this work.

Funding Information Open access funding provided by Royal Institute of Technology.

\section{Compliance with Ethical Standards}

This study was partly funded by the Swedish Energy Agency under contracts 45387-1 and 45514-1. The authors declare that there are no conflicts of interest. The research has not involved human participants and/or animals.

\section{Appendix}

An electrode layer subjected to a prescribed curvature $\kappa$ is considered, see Fig. 11. It is assumed that the active layer is well bonded to the metal foil and that the electrode is instantly bent to the initial U-shape with curvature $\kappa(t)=\kappa_{0} H(t)$, where $H(t)$ is the Heaviside function.

The strain acting at any point having coordinate, $\mathrm{z}$ can be written as

$\epsilon(z, t)=\kappa(t) z+\epsilon_{0}(t)$

For a pure elastic material response, the force across the cross-section of electrode is given by,

$$
\begin{aligned}
F=\int_{-t_{2}}^{t_{1}} \sigma b \mathrm{~d} z= & E_{1} \epsilon_{0} t_{1} b+E_{2} \epsilon_{0} t_{2} b \\
& +E_{1} \kappa_{0} \frac{t_{1}{ }^{2}}{2} b-E_{2} \kappa_{0} \frac{t_{2}^{2}}{2} b
\end{aligned}
$$

and the force equilibrium gives,

$$
\epsilon_{0}=\left(\frac{E_{2} \frac{t_{2}{ }^{2}}{2}-E_{1} \frac{t_{1}{ }^{2}}{2}}{E_{1} t_{1}+E_{2} t_{2}}\right) \kappa_{0}
$$


The moment across the cross-section is given by,

$$
\begin{aligned}
M_{\text {predicted }}= & E_{1} \varepsilon_{0} \frac{t_{1}{ }^{2}}{2} b-E_{2} \varepsilon_{0} \frac{t_{2}^{2}}{2} b+E_{1} \mathrm{~K}_{0} \frac{t_{1}^{3}}{3} b \\
& +E_{2} \mathrm{~K}_{0} \frac{t_{2}{ }^{3}}{3} b
\end{aligned}
$$

and according to Eq. (8), the predicted moment across the cross-section becomes,

$$
M_{\text {predicted }}=\left(-\frac{b\left(E_{2} \frac{t_{2}{ }^{2}}{2}-E_{1} \frac{t_{1}^{2}}{2}\right)^{2}}{E_{1} t_{1}+E_{2} t_{2}}+\frac{b}{3}\left(E_{1} t_{1}{ }^{3}+E_{2} t_{2}{ }^{3}\right)\right) \kappa_{0}
$$

The elastic solution can be utilized to formulate a viscoelastic solution by use of the viscoelastic correspondence principle. The viscoelastic response of the cathode active layer is defined by,

$\sigma(t)=\int_{o^{-}}^{t} E_{1}(t-\tau) \frac{d \epsilon}{d \tau} d \tau$

where $E_{1}$ is the relaxation modulus.

Here, the elastic modulus of Aluminum $\left(E_{2}\right)$ remains constant whereas the active layer $\left(E_{1}\right)$ shows a relaxation behavior and is time-dependent. The viscoelastic relaxation modulus of the active layer $E_{1}(t)$ is here approximated by a Prony series with parameters $\mathrm{P}, \mathrm{Q}, \mathrm{R}$, $\mathrm{M}$, and $\mathrm{N}$.

$E_{1}(t)=P+Q e^{-R t}+M e^{-N t}$

The Laplace transformed relaxation modulus then reads,

$\mathcal{L} E_{1}=\widetilde{E_{1}}=\left(\frac{P}{s}+\frac{Q}{s+R}+\frac{M}{s+N}\right)$

Using Eq. (13), the Laplace transformed solution for the bending moment in Eq. (10) is obtained using the viscoelastic correspondence principle. An inverse Laplace transformation gives the solution as a function of time as,

$M_{\text {predicted }}=X\left[t_{1}, t_{2}, P, Q, R, M, N, t\right] \cdot \kappa_{0}$

where $\mathrm{X}$ is a function of Prony series parameters, layer thicknesses and time.

It is observed that the function $\mathrm{X}$ represents the relaxation bending stiffness of the electrode. Using the U-shape bending formulation described in Eq. (3), the predicted force can be written as,

$P_{\text {predicted }}=X\left[t_{1}, t_{2}, P, Q, R, M, N, t\right] \cdot\left(\frac{1.695}{\Delta}\right)^{2}$
A stress relaxation test is performed by moving the faceplates from $\Delta=30 \mathrm{~mm}$ to $\Delta=15 \mathrm{~mm}$. The faceplates are held in a constant position for $6 \mathrm{~h}$. The forces obtained from experiment, $P_{\text {exp }}$, are recorded and plotted against time, see Fig. 9 , both in tension and compression configuration. The leastsquare method is utilized in order to find the best curve fit to the experimental data. The goal is to find the Prony series parameters used in Eq. (15) that fits the experimental data. The fit of the model at a data point is measured by its residual, defined as the difference between the force obtained experimentally $\left(P_{\text {exp }}\right)$ and the force predicted by model $\left(P_{\text {predicted }}\right)$. The least-square method finds the optimal parameter values by minimizing the sum, $r$, of squared.

residuals as,

$\min (r)=\sum_{i=1}^{n}\left(P_{\text {predicted }, i}-P_{\text {exp }, i}\right)^{2}$

where $n$ is the total number of data points.

The viscoelastic parameters $\mathrm{P}, \mathrm{Q}, \mathrm{R}, \mathrm{M}$, and $\mathrm{N}$ are found iteratively using the 'trust-region reflective' algorithm in MATLAB's lsqnonlin function [38]. The goodness-of-fit is evaluated by minimizing the residual $r$.

Open Access This article is licensed under a Creative Commons Attribution 4.0 International License, which permits use, sharing, adaptation, distribution and reproduction in any medium or format, as long as you give appropriate credit to the original author(s) and the source, provide a link to the Creative Commons licence, and indicate if changes were made. The images or other third party material in this article are included in the article's Creative Commons licence, unless indicated otherwise in a credit line to the material. If material is not included in the article's Creative Commons licence and your intended use is not permitted by statutory regulation or exceeds the permitted use, you will need to obtain permission directly from the copyright holder. To view a copy of this licence, visit http://creativecommons.org/licenses/by/4.0/.

\section{References}

1. Zheng H, Tan L, Liu G, Song X, Battaglia VS (2012) Calendering effects on the physical and electrochemical properties of $\mathrm{Li}[\mathrm{Ni} 1 /$ 3Mn 1/3Co 1/3]O 2 cathode. J Power Sources 208:52-57. https:// doi.org/10.1016/j.jpowsour.2012.02.001

2. Baunach M, Jaiser S, Schmelzle S, Nirschl H, Scharfer P, Schabel W (2016) Delamination behavior of lithium-ion battery anodes: influence of drying temperature during electrode processing. Dry Technol 34:462-473. https://doi.org/10.1080/07373937.2015. 1060497

3. Haselrieder W, Ivanov S, Christen DK, Bockholt H, Kwade A (2012) Impact of the calendering process on the interfacial structure and the related electrochemical performance of secondary lithiumion batteries. ECS Trans 50:59-70. https://doi.org/10.1149/05026. 0059ecst

4. Nadimpalli SPV, Sethuraman VA, Abraham DP, Bower AF, Guduru PR (2015) Stress evolution in lithium-ion composite electrodes during electrochemical cycling and resulting internal pressures on the cell casing. J Electrochem Soc 162:A2656-A2663. https://doi.org/10.1149/2.0341514jes 
5. Mukhopadhyay A, Sheldon BW (2014) Deformation and stress in electrode materials for Li-ion batteries. Prog Mater Sci 63:58-116. https://doi.org/10.1016/j.pmatsci.2014.02.001

6. Mohtat P, Nezampasandarbabi F, Mohan S, Siegel JB, Stefanopoulou AG, James A, Uddin K, Chouchelamane GH, Suttman A, Gong X, De Hoog J, Fleurbaey K, Nikolian A, Timmermans J, Van Mierlo J, Van Den Bossche P, Williard ND, Vetter J, Novák P, Wagner MR, Veit C, Möller KC, Besenhard JO, Winter M, Wohlfahrt-Mehrens M, Vogler C, Hammouche A, Wikner E (2017) Aging phenomena for Lithium-ion batteries. J Power Sources 147:98-103. https://doi.org/10.1016/j.jpowsour. 2005.01.006

7. Armand M (2001) Nature Lithium battery. Nature. 414:359-367. https://doi.org/10.1038/35104644

8. Jones EMC, Silberstein MN, White SR, Sottos NR (2014) In situ measurements of strains in composite battery electrodes during electrochemical cycling. Exp Mech 54:971-985. https://doi.org/ 10.1007/s11340-014-9873-3

9. Çapraz S, Rajput S, White NR (2018) Sottos, strain evolution in Lithium manganese oxide electrodes. Exp Mech 58:561-571. https://doi.org/10.1007/s11340-018-0381-8

10. Zhang J, Lu B, Song Y, Ji X (2012) Diffusion induced stress in layered Li-ion battery electrode plates. J Power Sources 209:220 227. https://doi.org/10.1016/j.jpowsour.2012.02.104

11. Lu B, Song Y, Guo Z, Zhang J (2013) Modeling of progressive delamination in a thin film driven by diffusion-induced stresses. Int J Solids Struct 50:2495-2507. https://doi.org/10.1016/j.ijsolstr. 2013.04.003

12. Zhao Y, Stein P, Bai Y, Al-Siraj M, Yang Y, Xu BX (2019) A review on modeling of electro-chemo-mechanics in lithium-ion batteries. J Power Sources 413:259-283. https://doi.org/10.1016/j.jpowsour. 2018.12.011

13. CE. Division (n.d.), Diagnostic examination of generation 2 Lithium-ion cells and assessment of performance degradation mechanisms prepared by chemical engineering Division, assessment

14. Sethuraman VA, Chon MJ, Shimshak M, Srinivasan V, Guduru PR (2010) In situ measurements of stress evolution in silicon thin films during electrochemical lithiation and delithiation. J Power Sources 195:5062-5066. https://doi.org/10.1016/j.jpowsour.2010.02.013

15. Rosolen JM (1996) Stress in carbon film electrodes during Li[sup +] electrochemical intercalation. J Electrochem Soc 143:2417. https://doi.org/10.1149/1.1837024

16. Chason E, Sheldon BW (2003) Monitoring stress in thin films during processing. Surf Eng 19:387-391. https://doi.org/10.1179/ 026708403225010118

17. Qi Y, Harris SJ (2010) In situ observation of strains during Lithiation of a graphite electrode. J Electrochem Soc 157:A741. https://doi.org/10.1149/1.3377130

18. de Vasconcelos LS, Xu R, Zhao K (2017) Operando Nanoindentation: a new platform to measure the mechanical properties of electrodes during electrochemical reactions. J Electrochem Soc 164:A3840-A3847. https://doi.org/10.1149/2. 1411714jes

19. Bucci G, Nadimpalli SPV, Sethuraman VA, Bower AF, Guduru PR (2014) Measurement and modeling of the mechanical and electrochemical response of amorphous Si thin film electrodes during cyclic lithiation. J Mech Phys Solids 62:276-294. https://doi.org/ 10.1016/j.jmps.2013.10.005

20. Pharr M, Suo Z, Vlassak JJ (2013) Measurements of the fracture energy of lithiated silicon electrodes of Li-ion batteries, Nano Lett. https://doi.org/10.1021/nl403197m

21. de Vasconcelos LS, Sharma N, Xu R, Zhao K (2019) In-situ Nanoindentation measurement of local mechanical behavior of a
Li-ion battery cathode in liquid electrolyte. Exp Mech 59:337-347. https://doi.org/10.1007/s11340-018-00451-6

22. Zhu J, Zhang X, Sahraei E, Wierzbicki T (2016) Deformation and failure mechanisms of 18650 battery cells under axial compression. J Power Sources 336:332-340. https://doi.org/10.1016/j.jpowsour. 2016.10.064

23. Zhang C, Xu J, Cao L, Wu Z, Santhanagopalan S (2017) Constitutive behavior and progressive mechanical failure of electrodes in lithium-ion batteries. J Power Sources 357:126-137. https://doi.org/10.1016/j.jpowsour.2017.04.103

24. Lai WJ, Ali MY, Pan J (2014) Mechanical behavior of representative volume elements of lithium-ion battery modules under various loading conditions. J Power Sources 248:789-808. https://doi.org/ 10.1016/j.jpowsour.2013.09.128

25. Zhu J, Zhang X, Luo H, Sahraei E (2018) Investigation of the deformation mechanisms of lithium-ion battery components using in-situ micro tests. Appl Energy 224:251-266. https://doi.org/10. 1016/j.apenergy.2018.05.007

26. Sahraei E, Bosco E, Dixon B, Lai B (2016) Microscale failure mechanisms leading to internal short circuit in Li-ion batteries under complex loading scenarios. J Power Sources 319:56-65. https:// doi.org/10.1016/j.jpowsour.2016.04.005

27. Lai WJ, Ali MY, Pan J (2014) Mechanical behavior of representative volume elements of lithium-ion battery cells under compressive loading conditions. J Power Sources 245:609-623. https://doi.org/ 10.1016/j.jpowsour.2013.06.134

28. Larsson PL (2001) Investigation of sharp contact at rigid-plastic conditions. Int J Mech Sci 43:895-920. https://doi.org/10.1016/ S0020-7403(00)00056-4

29. Pharr GM (1992) An improved technique for determining hardness and elastic modulus using load and displacement sensing indentation experiments. J Mater Res 7:1564-1583. https://doi.org/10. 1557/JMR.1992.1564

30. Chen Z, Christensen L, Dahn JR (2003) A study of the mechanical and electrical properties of a polymer/carbon black binder system used in battery electrodes. J Appl Polym Sci 90:1891-1899. https:// doi.org/10.1002/app.12863

31. Wu W, Xiao X, Wang M, Huang X (2014) A microstructural resolved model for the stress analysis of lithium-ion batteries. J. Electrochem. Soc. 161. https://doi.org/10.1149/2.082405jes

32. Matthewson MJ, Kurkjian CR, Gulati ST (1986) Strength measurement of optical fibers by bending. J Am Ceram Soc 69:815-821. https://doi.org/10.1111/j.1151-2916.1986.tb07366.x

33. ASM International Handbook Committee (1998), ASM Handbook: Materials characterization, volume 10 , book

34. LS. de Vasconcelos, R. Xu, J. Li, K. Zhao (2016), Grid indentation analysis of mechanical properties of composite electrodes in $\mathrm{Li}$-ion batteries, Extrem. Mech. Lett. doi:https://doi.org/10.1016/j.eml. 2016.03.002, Grid indentation analysis of mechanical properties of composite electrodes in Li-ion batteries

35. Xu R, Sun H, De Vasconcelos LS, Zhao K (2017) Mechanical and structural degradation of LiNixMnyCozO2 cathode in Li-ion batteries: an experimental study. J Electrochem Soc 164:A3333-A3341. https://doi.org/10.1149/2.1751713jes

36. ABAQUS, Abaqus 6.14, Dassault Systèmes Simulia Corp., Providence, RI, USA (2014)

37. Storåkers B, Fleck NA, McMeeking RM (1999) The viscoplastic compaction of composite powders. J Mech Phys Solids 47:785815. https://doi.org/10.1016/S0022-5096(98)00076-3

38. MATLAB R2018a, the MathWorks, Inc, N

Publisher's Note Springer Nature remains neutral with regard to jurisdictional claims in published maps and institutional affiliations. 